\title{
Pro-inflammatory and anti-inflammatory compounds exert similar effects on Pglycoprotein in blood-brain barrier endothelial cells
}

DOI:

10.1111/jphp.12893

\section{Document Version}

Accepted author manuscript

Link to publication record in Manchester Research Explorer

Citation for published version (APA):

Torres Vergara, P., \& Penny, J. (2018). Pro-inflammatory and anti-inflammatory compounds exert similar effects on Pglycoprotein in blood-brain barrier endothelial cells. Journal of Pharmacy and Pharmacology, 70(6). https://doi.org/10.1111/jphp.12893

Published in:

Journal of Pharmacy and Pharmacology

\section{Citing this paper}

Please note that where the full-text provided on Manchester Research Explorer is the Author Accepted Manuscript or Proof version this may differ from the final Published version. If citing, it is advised that you check and use the publisher's definitive version.

\section{General rights}

Copyright and moral rights for the publications made accessible in the Research Explorer are retained by the authors and/or other copyright owners and it is a condition of accessing publications that users recognise and abide by the legal requirements associated with these rights.

\section{Takedown policy}

If you believe that this document breaches copyright please refer to the University of Manchester's Takedown Procedures [http://man.ac.uk/04Y6Bo] or contact uml.scholarlycommunications@manchester.ac.uk providing relevant details, so we can investigate your claim.

\section{OPEN ACCESS}




\title{
Pro-inflammatory and anti-inflammatory compounds exert similar effects on P- glycoprotein in blood-brain barrier endothelial cells
}

\author{
Torres-Vergara $\mathrm{P}^{1,2}$, Penny $\mathrm{JI}^{1}$ \\ 1. Division of Pharmacy and Optometry, School of Health Sciences, Faculty of Medicine, \\ Biology and Health, University of Manchester, Oxford Road, Manchester, M13 9PL, United \\ Kingdom \\ 2. Department of Pharmacy, Faculty of Pharmacy, University of Concepción, Barrio \\ Universitario, Concepción, Chile
}

Corresponding author e-mail: jeffrey.penny@manchester.ac.uk

\begin{abstract}
Objectives: The effects of anti-inflammatory glucocorticoids dexamethasone (DX) and hydrocortisone (HC), pro-inflammatory cytokine interleukin-1 $(\mathrm{IL}-1 \beta)$ and dietary long-chain polyunsaturated fatty acids (PUFAs) on expression and activity of the ATP-binding cassette transporter P-glycoprotein (P-GP) were studied in porcine brain endothelial cells (PBECs).

Methods: Primary PBECs were treated for $24 \mathrm{~h}$ with glucocorticoids, IL- $1 \beta$ and long-chain PUFAs. P-GP activity was determined by measuring intracellular calcein accumulation and PGP expression by Western blotting. The effect of PUFAs on membrane fluidity was assessed by fluorescence recovery after photobleaching (FRAP).
\end{abstract}

Key findings: Dexamethasone, HC, and IL-1 $\beta$ significantly increased P-GP expression and activity. The effect of IL-1 $\beta$ was attenuated by the IL-1 receptor antagonist (IL-1RA). This is the first report of the combined actions of IL-1 $\beta$ and IL-1RA on P-GP expression and the first evidence of glucocorticoid-mediated P-GP up-regulation in PBECs. Arachidonic acid (AA), docosahexaenoic acid (DHA) and eicosapentenoic acid (EPA) significantly decreased P-GP activity without affecting expression or membrane fluidity. AA, DHA and EPA counteracted IL-1 $\beta$-mediated increases in P-GP activity, whilst AA and EPA, but not DHA, counteracted glucocorticoid-mediated increase in P-GP activity.

Conclusions: Whilst glucocorticoids and IL-1 $\beta$ possess opposing actions in inflammation, they demonstrate functional consistency by increasing P-GP expression and activity in PBECs. 
Keywords: P-glycoprotein, cytokine, interleukin, glucocorticoids, polyunsaturated fatty acid, PUFA, blood-brain barrier, endothelial cell.

\section{Introduction}

P-glycoprotein (P-GP), an ATP-binding cassette (ABC) transporter, expressed in bloodbrain barrier $(\mathrm{BBB})$ endothelial cells plays a key role in influencing central nervous system (CNS) drug disposition (1). P-glycoprotein activity has been widely reported to be modulated by direct interaction of inhibitors with the drug-binding sites of the transporter $(2,3)$.

However, modulation of P-GP activity via changes in gene expression has received increased attention. Studies report activation of both membrane and nuclear receptors in brain endothelial cells, leading to activation of signalling pathways, elicit changes in the expression of P-GP, and other ABC transporters, at both the gene and protein levels $(4,5)$.

Pro-inflammatory cytokines, including IL-1 $\beta$, IL-6 and TNF $\alpha$, are key elements in development and progression of multiple disease conditions and the effects of acute and chronic inflammatory conditions, mediated by pro-inflammatory cytokines, on the expression and activity of P-GP have been studied both in in vitro and in vivo models $(1,6)$. Since many therapeutic drugs are P-GP substrates, it is feasible that the pathophysiological mechanisms associated with disease conditions could influence CNS drug disposition.

Whilst studies consistently report that inflammatory conditions cause changes in the expression of P-GP at the protein level, these changes are both model- and time-dependent (7, 8). For example, Hartz et al. (7) demonstrated that a 6-hour treatment with TNF $\alpha$ up-regulated P-GP activity and expression in isolated rat capillaries, but Iqbal et al. (8) reported that a $24 \mathrm{~h}$ treatment with the same cytokine down-regulated P-GP activity in primary brain endothelial cell cultures isolated from gestating and post-natal guinea pigs. 
The majority of studies investigating the effects of sterile and non-sterile inflammatory conditions on P-GP expression and function at the blood-brain barrier have been undertaken in rodent-based in vivo and in vitro models (7-9), with the amount of work performed in models derived from higher species, particularly porcine (10) and human (11-13) cell-based models, being comparatively less.

The extent of an inflammatory response is a balance between pro- and antiinflammatory factors. Glucocorticoids possess anti-inflammatory activity, but are also reported to affect expression of $\mathrm{ABC}$ transporters in mammalian brain endothelial cells (14). However, the findings of the effects of glucocorticoids on P-GP expression in porcine-based BEC models are conflicting, as von Wedel-Parlow et al. (10) demonstrated HC decreased P-GP expression whilst Alms et al. (15) reported DX had no effect on P-GP activity.

Regulation of P-GP expression and activity is complex and multifactorial. The dietaryderived long chain polyunsaturated fatty acids DHA and EPA, which have been reported to exert anti-inflammatory actions (16), have also been demonstrated to decrease P-GP activity in CaCo-2 cells (17). However, AA, a prostaglandin precursor that is considered pro-inflammatory (18), has exhibited mixed effects on P-GP activity, with studies reporting P-GP induction (19) and P-GP inhibition (17).

Long-chain PUFAs may act through multiple mechanisms, but one that has received much attention is their ability to provoke changes in membrane fluidity (20). Such changes are thought to modulate the activity of membrane-bound receptors (16) and $\mathrm{ABC}$ transporters embedded within lipid rafts (21) and a number of reports have described the chemosensitising effects of PUFAs on cancer cell lines resistant to therapeutics that are P-GP substrates $(22,23)$. However, to date, no studies have investigated the ability of long-chain PUFAs to modulate the activity of P-GP in blood-brain barrier endothelial cells that express high levels of the transporter. Furthermore, previous studies have primarily looked at the effects of single inflammatory mediators on P-GP expression. The current studies are the first to investigate the interplay between pro-inflammatory mediators (IL-1 $\beta$ and AA) and anti-inflammatory 
mediators (DX, HC, DHA and EPA) and their combined effects on both P-GP expression and functional activity in primary PBECs.

Our previous studies have demonstrated this model is competent in terms of demonstrating key physiological features of the blood-brain barrier, including formation of a highly restrictive endothelial cell monolayer with high transendothelial electrical resistance, expression of functional ABC efflux transporters (24) and interleukin-1 receptor (25).

\section{Materials and methods}

\section{Reagents and materials}

All chemicals and mouse anti- $\beta$-actin-N-terminal monoclonal antibody were obtained from Sigma-Aldrich, UK. Porcine recombinant IL-1 $\beta$ and IL-1RA were obtained from R\&D Systems, USA. Calcein-AM, cell culture reagents and Vybrant $^{\circ}$ DiI dye were purchased from Life Technologies, UK. Bovine plasma-derived serum was obtained from First Link Biochemicals, UK. Collagenase, DNAase and trypsin were obtained from Worthington Biochemicals, USA. Mouse C219 monoclonal antibody was obtained from Calbiochem, USA and horseradish peroxidase (HRP)-conjugated sheep anti-mouse antibody obtained from General Electric Life Sciences, UK. Clarity ECL developing reagent was from Bio-Rad, UK. The CTX-TNA2 rat astrocyte cell line was obtained from the American Type Culture Collection (ATCC) repository.

Culturing of the CTX-TNA2 rat astrocyte cell line and harvesting of astrocyte-conditioned medium

The CTX-TNA2 cell line was cultured in phenol red-free high-glucose DMEM, supplemented with $10 \%(\mathrm{v} / \mathrm{v})$ FBS and $1 \%(\mathrm{v} / \mathrm{v})$ penicillin/streptomycin. Astrocyteconditioned medium (ACM) was harvested when astrocytes reached $40-60 \%$ confluency, filtered through a $0.22 \mu \mathrm{m}$ sterile syringe filter and stored at $-20^{\circ} \mathrm{C}$. 


\section{Isolation and culturing of porcine brain microvessels}

Microvessels were isolated from fresh porcine brains based on the protocol of Skinner et al (2009). Cryopreserved microvessels were thawed and resuspended in phenol red-free lowglucose DMEM supplemented with $10 \%(\mathrm{v} / \mathrm{v})$ bovine plasma derived serum, $2 \mathrm{mM}$ Lglutamine, $1 \%(\mathrm{v} / \mathrm{v})$ penicillin/streptomycin and $125 \mu \mathrm{g} \cdot \mathrm{ml}^{-1}$ heparin (PBEC growth medium), seeded into rat type I collagen $\left(125 \mu \mathrm{g} \cdot \mathrm{ml}^{-1}\right) /$ fibronectin $\left(7.5 \mu \mathrm{g} \cdot \mathrm{ml}^{-1}\right)$ coated 6-well plates and incubated at $37{ }^{\circ} \mathrm{C}$ with $5 \% \mathrm{CO}_{2}$ for $24 \mathrm{~h}$. Microvessels were treated with puromycin, $4 \mu \mathrm{g} \cdot \mathrm{ml}^{-1}$ for $48 \mathrm{~h}$ and subsequently maintained in 1:1 PBEC growth medium:ACM for 7 days (Western blotting) or subcultured on day 5 into collagen/fibronectin-coated 96-well plates, 20,000 cells/well (calcein-AM assay) and 30,000 cells/well in Ibidi $\mu$-Slide 8-well microscopy chambers (FRAP experiments).

\section{Treatment with pro-inflammatory and anti-inflammatory compounds}

PBECs were maintained in treatment medium comprised of phenol red-free low-glucose DMEM supplemented with $1 \%(\mathrm{v} / \mathrm{v}) \mathrm{FBS}$ and $2 \mathrm{mM}$ L-glutamine. After $1 \mathrm{~h}$ equilibration, PBECs were incubated with the glucocorticoids DX and HC, the cytokines IL-1 $\beta$, IL-1RA and the long chain PUFAs AA, DHA and EPA (at concentrations stated in individual Figures) at 37 ${ }^{\circ} \mathrm{C}$ with $5 \% \mathrm{CO}_{2}$ for $24 \mathrm{~h}$. Glucocorticoids stock solutions were made up in DMSO, sodium salts of PUFAs were dissolved in absolute ethanol and cytokines were reconstituted in sterile phosphate buffered saline (PBS). For all treatments, the concentration of DMSO and ethanol never exceeded $0.1 \%(\mathrm{v} / \mathrm{v})$ and $0.05 \%(\mathrm{v} / \mathrm{v})$, respectively, and this concentration of solvent did not significantly affect $\mathrm{ABCB} 1$ activity. Compounds were used at non-cytotoxic concentrations, as determined in advance by the MTT assay.

\section{Calcein-AM assay for measurement of P-glycoprotein activity}

PBECs in 96-well plates were washed twice with warm PBS and equilibrated with phenol red-free low-glucose DMEM supplemented with $2 \mathrm{mM}$ L-glutamine at $37{ }^{\circ} \mathrm{C}$ with $5 \%$ 
$\mathrm{CO}_{2}$ for $30 \mathrm{~min}$. Where appropriate, cells were pre-incubated with the P-GP inhibitor verapamil (final concentration $10 \mu \mathrm{M}$ ) for $30 \mathrm{~min}$.

PBEC monolayers were incubated with calcein-AM (final concentration $0.5 \mu \mathrm{M}$ ) for $30 \mathrm{~min}$. washed twice with ice-cold PBS and $100 \mu$ of PBS was added to each well. Fluorescence was measured immediately (excitation: $484 \mathrm{~nm}$, emission $530 \mathrm{~nm}$ ) using a Safire multi-plate reader (Tecan, Switzerland) and expressed as relative fluorescence units (RFU) normalised to $\mu \mathrm{g}$ of protein. Protein content of cell lysates was determined using the Bradford reagent (Bio Rad, UK).

\section{Western blotting}

PBECs were treated with the selected compounds and lysed with $200 \mu$ of Cellytic M solution. Lysates were centrifuged at $15000 \mathrm{x}$ g at $4{ }^{\circ} \mathrm{C}$ for $15 \mathrm{~min}$ and supernatants stored at -80 ${ }^{\circ} \mathrm{C}$. Protein content of cell lysates was determined using the Bradford reagent (Bio Rad, UK).

Fifteen $\mu \mathrm{g}$ protein was loaded on a $6 \%$ SDS-polyacrylamide gel, electrophoresis carried out at $150 \mathrm{~V}$ and proteins were subsequently electrotransferred to polyvinylidene difluoride membranes. Membranes were incubated overnight with C219 monoclonal antibody for detection of P-GP (1:50) and mouse anti- $\beta$-actin-N-terminal monoclonal antibody $(1: 25,000)$ for $1.5 \mathrm{~h}$. Membranes were washed with TBS-T then incubated with HRP-conjugated sheep antimouse antibody $(1: 2,500)$. Proteins were detected by enhanced chemiluminescence using the ChemiDoc imaging system (Bio Rad, UK) and images analysed with ImageJ software (National Institute of Health, USA).

\section{Fluorescence recovery after photobleaching}

PBECs in Ibidi $\mu$-Slide 8-well microscopy chambers were treated with PUFAs, washed three times with warm Hank's balanced salt solution and incubated for 20 min with Vybrant DiI reagent. After three 5 min washes, $300 \mu \mathrm{l}$ of warm HBSS were added to each well. 
Fluorescence recovery after photobleaching (FRAP) was analysed with a Leica TCS SP5 AOBS inverted confocal microscope (Leica, Germany) with an excitation wavelength of $568 \mathrm{~nm}$. Bleaching was carried out in the region of interest (ROI) at $488 \mathrm{~nm}$ for $1 \mathrm{~s}$.

Images were analysed with LAS AF lite software (Leica, Germany) and the extracted data processed using the double normalisation method (Kenworthy, 2007).

The post-bleaching portion of fractional fluorescence recovery curves over time were fitted under an exponential decay function, using the Prism 6.0 statistical software (GraphPad, USA), to obtain the half-time of recovery $\left(\mathrm{t}^{1 / 2}\right)$ parameter. The diffusion coefficient $(D)$ was determined with the following equation (Yamamoto and Ando, 2013).

$$
D=\frac{\omega^{2}}{4 t_{1 / 2}}
$$

Where $\omega$ is the radius of the focused laser beam.

\section{Statistical analysis}

Data are expressed as mean \pm standard deviation and analysed with either the MannWhitney test or Kruskal-Wallis test with Dunn's post hoc analysis, using Prism 6.0 statistical software (GraphPad, USA).

\section{Results}

\section{Effect of glucocorticoids on P-glycoprotein activity and expression}

PBECs were successfully isolated and maintained in culture ( $>99 \%$ purity) prior to treatment. Treatment of PBECs for $24 \mathrm{~h}$ with dexamethasone and hydrocortisone (at a concentration of $10 \mu \mathrm{M})$, significantly decreased $(\mathrm{P}<0.0001)$ the intracellular accumulation of calcein by $25 \%$ and $20 \%$ respectively, suggesting increased P-GP activity (Figure 1A). Neither of the compounds affected cell viability at the concentration used.

Western blotting of whole cell lysates followed by densitometric analysis revealed expression of the P-GP transporter was significantly up-regulated $(\mathrm{P}<0.05)$ after treatment with 
the selected glucocorticoids (Figure 1B and 1C), confirming the effects of glucocorticoids on P-

GP at a functional level.

Figure 1. Effects of glucocorticoids on P-GP activity and expression in brain endothelial cells. (A) effects of DX and $\mathrm{HC}$ on intracellular calcein accumulation, (B) effects of DX and $\mathrm{HC}$ on $\mathrm{P}$-GP expression and $(\mathrm{C})$ fold change in P-GP band intensity normalised to the $\beta$-actin loading control. Results are expressed as mean \pm standard deviation of three independent experiments. $*: \mathrm{P}<0.05, * * * *: \mathrm{P}<0.0001$.

\section{Effect of the pro-inflammatory cytokine Interleukin-1ß on P-glycoprotein activity and expression}

Treatment of PBECs with IL-1 $\beta$ decreased the intracellular accumulation of calcein, with this reduction being significant at concentrations of $1 \mathrm{ng} \cdot \mathrm{ml}^{-1}$ ( $25 \%$ reduction compared to the control, $\mathrm{P}<0.0001$ ) and above (Figure $2 \mathrm{~A}$ ). The specificity of the effect of IL-1 $\beta$ on P-GP activity was assessed using IL-1 receptor antagonist (IL-1RA). IL-1RA counteracted the IL-1 $\beta$ mediated reduction in intracellular calcein accumulation, with levels of calcein accumulation reverting to a similar level observed in the control condition, (Figure 2B). Treatment of PBECs with 1,000 ng.ml ${ }^{-1}$ IL-1RA alone did not significantly affect intracellular calcein accumulation.

The IL-1 $\beta$-mediated increase in P-GP activity and the counteracting effect of IL-1RA, were confirmed by Western blotting. Densitometric analysis demonstrated that IL-1 $\beta$ significantly $(\mathrm{P}<0.05)$ up-regulated P-GP expression, whilst IL-1RA partially, but significantly $(\mathrm{P}<0.05)$, attenuated this effect (Figures $2 \mathrm{C}$ and 2D).

Figure 2. Effects of IL-1 $\beta$ and IL-1RA on P-GP activity and expression in brain endothelial cells. (A) effect of IL-1 $\beta$ on P-GP activity, (B) effect of IL-1RA on IL-1 $\beta$-induced P-GP activity, (C) effects of IL-1RA and IL-1 $\beta$ on P-GP expression and (D) the fold change in the PGP band intensity normalised to the $\beta$-actin loading control. Results are expressed as mean \pm standard deviation of three independent experiments (duplicate for IL-1RA single treatment). *: $\mathrm{P}<0.05, * *, \# \#: \mathrm{P}<0.01, * * *$, \#\#: $\mathrm{P}<0.001, * * * *: \mathrm{P}<0.0001$. 


\section{Effect of n-3 and n-6 PUFAs on P-glycoprotein activity and expression}

Treatment of PBECs with AA, DHA and EPA for $24 \mathrm{~h}$ significantly increased the intracellular accumulation of calcein, reflecting reduced P-GP activity (Figure 3A).

Despite significantly reducing P-GP activity, AA, DHA or EPA did not significantly modify P-GP expression (Figures 3B and 3C).

Figure 3. Effects of long-chain PUFAs on P-GP activity and expression. (A) effects of AA, DHA and EPA on intracellular calcein accumulation and (B) effects of AA, DHA and EPA on P-GP expression. (C) fold change in the P-GP band intensity normalised to the $\beta$-actin loading control. Results are expressed as mean \pm standard deviation of three independent experiments. $* * * *: \mathrm{P}<0.0001$.

\section{Effect of PUFAs on glucocorticoid-induced and IL-1ß-induced P-glycoprotein activity}

Treatment of PBECs with IL-1 $\beta$, DX and HC significantly increased P-GP functional activity, whilst treatment with AA, DHA and EPA significantly reduced P-GP activity. Therefore, the ability of PUFAs to reverse IL-1 $\beta-$, DX- and HC-induced P-GP functional activity was investigated. AA, DHA and EPA counteracted IL-1 $\beta$-mediated increases in P-GP activity in brain endothelial cells, reducing calcein accumulation to control values, whilst AA and EPA, but not DHA, counteracted the HC- and DX-mediated increases in P-GP activity (Table 1).

Table 1. Effect of AA, DHA and EPA on glucocorticoid- and IL-1 $\beta$-induced P-GP activity, expressed as $\%$ RFU/ $\mu$ g protein. Single treatments with glucocorticoids, IL- $1 \beta$ and PUFAs were compared to their respective control. The effect of co-treatments on intracellular calcein accumulation was assessed by comparing the results of the co-treatments with the single treatments of glucocorticoid or IL-1 $\beta$. Results are expressed as mean \pm standard deviation of three independent experiments. \#: glucocorticoid or IL-1 $\beta$ single treatments $\mathrm{v} / \mathrm{s}$ control; $\S$ : PUFA single treatments $\mathrm{v} / \mathrm{s}$ control; *: co-treatments $\mathrm{v} / \mathrm{s}$ glucocorticoid or IL- $1 \beta$ single treatments. \#, §, *: $\mathrm{P}<0.05 ; \# \#, \S \S, * *: \mathrm{P}<0.01 ; \# \# \#, \S \S \S, * * *: \mathrm{P}<0.001 ; \# \# \#, \S \S \S \S, * * * *: \mathrm{P}$ $<0.0001$; ns: not significant.

In order to establish if the actions of AA, DHA and EPA occurred solely at the functional level, or whether the PUFAs modified P-GP expression, Western blotting of whole 
cell lysates was performed. Western blotting and densitometric analysis confirmed that PUFAs did not affect IL-1 $\beta-$, DX- and HC-induced P-GP expression (Figure 4).

Figure 4. Representative Western blots (A, C and E) and densitometric analysis (B, D, and F) of the effects of AA, DHA and EPA on (A) DX-induced P-GP expression, (B) HC-induced PGP expression and (C) IL-1 $\beta$-induced P-GP expression in brain endothelial cells.

\section{Effect of n-3 and n-6 PUFAs on membrane fluidity}

The PUFAs AA, DHA and EPA significantly reduced P-GP activity in porcine brain endothelial cells, independent of modifying P-GP expression. Since P-GP is an integral membrane protein, the effect of PUFAs on membrane fluidity was therefore analysed.

When PBECs were treated with AA, DHA and EPA, fitted average fractional fluorescence recovery curves were similar to controls. Treatment with AA, DHA and EPA did not significantly modify either the mobile fraction or the diffusion coefficient values of DiI18 when compared to control conditions, indicating a lack of effect of long-chain PUFAs on membrane fluidity at the concentrations employed in these studies (Figure 5).

Figure 5. The effect of AA, DHA and EPA on membrane fluidity of PBECs. (A) Average fitted fractional fluorescence recovery curves and (B) diffusion coefficients calculated from the halflives obtained after exponential decay fitting of FRAP curves. Data are expressed as the mean \pm standard deviation of three independent experiments.

\section{Discussion}

P-glycoprotein activity influences whole body pharmacokinetics and drug delivery to the CNS. Consequently, alteration of P-GP activity may impact CNS drug disposition and delivery efficacy.

Inflammatory conditions are associated with numerous pathological states that involve high levels of IL-1ß $(26,27)$, including stroke (28) and psychiatric and neurodegenerative 
conditions (27). Whilst the individual effects of IL-1 $\beta$, or of anti-inflammatory glucocorticoids and PUFAs, on P-GP expression and activity have been reported previously $(7,11,29)$, few studies have analysed the interplay between pro- and anti-inflammatory mediators on BBB PGP the expression and activity (10). Therefore, the current study investigated the effects of proand anti-inflammatory compounds on P-GP expression and activity in primary PBECs

In the current study, IL-1 $\beta$ increased P-GP activity and expression, which were attenuated by IL-1RA, confirming involvement of the IL-1 $\beta$ receptor. This is the first experimental evidence that IL-1RA antagonises IL-1 $\beta$-mediated induction of an ABC transporter. The effects of IL-1 $1 \beta$ on P-GP expression are consistent with the studies of Zuloaga et al. (12) that demonstrated IL-1 $\beta$ increased P-GP expression in human BECs.

In contrast to the findings of the present work, von Wedel-Parlow et al. (10) and Iqbal et al. (8) reported IL-1 $\beta$ decreased P-GP activity in porcine and rodent BECs, respectively. Although neither characterised the downstream events, they suggested involvement of the canonical NF- $\mathrm{BB}$ signalling pathway. This issue represented an opportunity to test several NF$\kappa \mathrm{B}$ inhibitors including BAY-117082, luteolin, cardamonin and sulfasalazine. However, as none of them attenuated the actions of IL-1 $\beta$ (data not shown), these findings suggest the IL-1 $\beta$ mediated induction of P-GP expression is more complex than thought and could involve the participation of other signalling pathways. Key candidates are the mitogen-activated protein kinase (MAPK) and c-Jun-N-terminal kinase (JNK) pathways which have been reported to be activated by pro-inflammatory cytokines IL- $1 \beta$ and tumour necrosis factor- $\alpha(30,31)$.

The glucocorticoids hydrocortisone and dexamethasone up-regulated P-GP expression and activity. This is the first evidence of glucocorticoid-mediated P-GP up-regulation in PBECs, and is in agreement with Narang et al. (14) and Iqbal et al. $(32,33)$, who demonstrated dexamethasone increased P-gp expression and activity in rat and guinea pig BECs.

However, a lack of effect of HC and DX on P-GP in PBECs has been reported $(10,15)$. Alms et al. (15) suggested puromycin might hinder the inductive actions of glucocorticoids, 
since puromycin is also a P-GP inducer. In the present studies both HC and DX significantly upregulated P-GP expression and activity and this may be explained by differences in exposure times to puromycin; $48 \mathrm{~h}$ in the current studies compared to $72 \mathrm{~h}$ employed by Alms et al (15). This reduced exposure time is likely to result in less of an inductive effect by puromycin and a greater inductive effect of HC and DX (and IL-1 $\beta$ ) on P-GP expression and activity.

Treatment with DHA, EPA and AA significantly increased intracellular calcein accumulation, potentially reflecting decreased P-GP activity. These findings are consistent with reports that long-chain PUFAs sensitise drug-resistant cells to chemotherapeutics that are P-GP substrates $(17,22,23)$.

P-GP is localised in plasma membrane lipid rafts (21) and studies in drug resistant HT29 cells (34) demonstrated DHA and EPA (but not AA) displaced cholesterol from lipid rafts, decreasing P-GP activity. Also, incorporation of PUFAs within the plasma membrane, decreases molecular order, affecting membrane fluidity $(16,35,36)$. In the current study, the AA-, DHA- and EPA-mediated reduction in P-GP activity was associated with no change in PGP expression level. To establish if the effects of long-chain PUFAs were through changes in plasma membrane fluidity, FRAP analysis was performed (37). Neither AA, EPA nor DHA significantly modified membrane diffusion coefficients.

One potential explanation for a change in P-GP activity with no change is membrane fluidity is that n-3 PUFAs, including DHA, increase the molecular order of lipid rafts, thereby affecting the activity of proteins embedded within these lipid microdomains (36). However, this does not explain why AA, an n-6 PUFA, elicited a similar effect as n-3 PUFAs on P-GP activity. Another possible explanation for reduced P-GP activity following exposure to DHA and EPA is PUFA-mediated internalisation of P-GP, as demonstrated by Gelsomino et al. (34). Therefore, further studies are required to determine if the changes in P-GP activity following treatment with long-chain PUFAs are due to alterations in membrane order, composition of lipid rafts and/or internalisation of the protein within the cell. 
Co-treatment of PBECs with the P-GP inducer IL-1 $\beta$ and with PUFAs (AA, DHA and EPA) revealed PUFAs counteract IL-1 $\beta$-mediated induction of P-GP activity. Similarly, AA and EPA, although not DHA, also counteract glucocorticoid (HC, DX)-mediated induction of P-GP activity.

Although glucocorticoids are anti-inflammatory and IL-1 $\beta$ is pro-inflammatory, they individually up-regulated P-GP expression and activity. In preliminary studies glucocorticoid and IL-1 $\beta$ co-treatments produced a synergistic effect on P-GP activity. HC increased P-GP activity by $20 \%$ and treatment with IL- $1 \beta$ increased P-GP activity by $25 \%$. However, cotreatment with $\mathrm{HC}$ and IL-1 $\beta$ increased P-GP activity by $40 \%$ (data not shown).

Synergism between anti- and pro-inflammatory mediators has been reported previously. Iqbal et al (33) demonstrated DX enhanced the effect of IL-1 $\beta$ on P-gp activity, proposing the synergistic effect is a result of the DX-mediated increase in IL-1 receptor type I expression, whose activation by IL-1 $\beta$ enhanced P-gp activity.

Whilst glucocorticoids routinely act through the glucocorticoid receptor pathway, the downstream events involved in the IL-1 $\beta$-mediated regulation of P-GP expression remain unclear as mentioned above, and further studies are underway to establish the mechanism by which IL-1 $\beta$ regulates P-GP expression in blood-brain barrier endothelial cells.

\section{Conclusions}

In this study, the pro-inflammatory cytokine IL-1 $\beta$ and the anti-inflammatory glucocorticoids DX and $\mathrm{HC}$ induced activity of the $\mathrm{ABC}$ transporter P-GP in porcine brain endothelial cells, whilst the long chain omega-3 PUFAs DHA and EPA and the omega-6 PUFA AA attenuated this induction, independent of altering membrane fluidity. This outcome demonstrates that anti-inflammatory molecules do not necessarily counteract the actions of proinflammatory molecules in all biochemical and physiological processes.

Acute and chronic inflammation, and IL-1 $\beta$ production, is associated with many widespread medical conditions, and has the potential to regulate P-GP efflux activity within the 
blood-brain barrier. Consequently, brain penetration of endogenous mediators and xenobiotics including therapeutic drugs may be altered in inflammatory conditions, and dietary-derived PUFAs could help restore P-GP activity to levels observed in non-inflammatory conditions.

\section{Declarations}

\section{Conflict of interests}

The authors declare they have no conflict of interest.

\section{Acknowledgements}

The National Commission of Science and Technological Research (CONICYT), Chile, funds Mr. Torres-Vergara's scholarship (reference: 14.598.737-7). Mr. Torres-Vergara also acknowledges the support from the University of Concepción, Chile and the Division of Pharmacy \& Optometry, University of Manchester, England, UK. The authors would like to thank the technical support provided by Dr. Steven Marsden from the Bioimaging Unit, Faculty of Biology, Medicine and Health, University of Manchester. Part of this work was presented at the 2015 Annual Conference of the British Pharmacological Society in London, United Kingdom.

\section{References}

1. Qosa H, Miller DS, Pasinelli P, Trotti D. Regulation of ABC efflux Transporters at Blood-brain barrier in health and neurological Disorders. Brain Res. 2015;1628(Pt.B):298 - 316. 
2. Thomas H, Coley HM. Overcoming multidrug resistance in cancer: an update on the clinical strategy of inhibiting p-glycoprotein. Cancer Control. 2003;10(2):159-165.

3. Zinzi L, Capparelli E, Cantore M, Contino M, Leopoldo M, Colabufo NA. Small and Innovative Molecules as New Strategy to Revert MDR. Front Oncol. 2014;4(2):1-12

4. Lemmen J, Tozakidis IE, Bele P, Galla HJ. Constitutive androstane receptor upregulates Abcb1 and Abcg2 at the blood-brain barrier after CITCO activation. Brain Res. $2013 ; 1501: 68-80$.

5. Lemmen J, Tozakidis IE, Galla HJ. Pregnane X receptor upregulates ABC-transporter Abcg2 and Abcb1 at the blood-brain barrier. Brain Res. 2013;1491:1-13.

6. Miller DS. Regulation of ABC transporters at the blood-brain barrier. Clin Pharmacol Ther. 2015;97(4):395-403.

7. Hartz AM, Bauer B, Fricker G, Miller DS. Rapid modulation of P-glycoproteinmediated transport at the blood-brain barrier by tumor necrosis factor-alpha and lipopolysaccharide. Mol Pharmacol. 2006;69(2):462-470.

8. Iqbal M, Ho HL, Petropoulos S, Moisiadis VG, Gibb W, Matthews SG. Proinflammatory cytokine regulation of P-glycoprotein in the developing blood-brain barrier. PLoS One. 2012;7(8):e43022.

9. Bauer B, Hartz AM, Miller DS. Tumor necrosis factor alpha and endothelin-1 increase P-glycoprotein expression and transport activity at the blood-brain barrier. Mol Pharmacol. 2007;71(3):667-675.

10. von Wedel-Parlow M, Wolte P, Galla HJ. Regulation of major efflux transporters under inflammatory conditions at the blood-brain barrier in vitro. $\mathrm{J}$ Neurochem. 2009;111(1):111-118.

11. Poller B, Drewe J, Krahenbuhl S, Huwyler J, Gutmann H. Regulation of BCRP (ABCG2) and P-glycoprotein (ABCB1) by cytokines in a model of the human bloodbrain barrier. Cell Mol Neurobiol. 2010;30(1):63-70.

12. Zuloaga KL, Swift SN, Gonzales RJ, Wu TJ, Handa RJ. The androgen metabolite, 5alpha-androstane-3beta,17beta-diol, decreases cytokine-induced cyclooxygenase-2, 
vascular cell adhesion molecule-1 expression, and P-glycoprotein expression in male human brain microvascular endothelial cells. Endocrinology. 2012;153(12):5949-5960.

13. Hembury A, Mabondzo A. Endothelin-1 reduces p-glycoprotein transport activity in an in vitro model of human adult blood-brain barrier. Cell Mol Neurobiol. 2008;28(7):915921.

14. Narang VS, Fraga C, Kumar N, Shen J, Throm S, Stewart CF, Waters CM. Dexamethasone increases expression and activity of multidrug resistance transporters at the rat blood-brain barrier. Am J Physiol Cell Physiol. 2008;295(2):C440-450.

15. Alms D, Fedrowitz M, Romermann K, Noack A, Loscher W. Marked Differences in the Effect of Antiepileptic and Cytostatic Drugs on the Functionality of P-Glycoprotein in Human and Rat Brain Capillary Endothelial Cell Lines. Pharm Res. 2014;31(16):1588 1604.

16. Calder PC. Fatty acids and inflammation: the cutting edge between food and pharma. Eur J Pharmacol. 2011;668 Suppl 1:S50-58.

17. Kuan CY, Walker TH, Luo PG, Chen CF. Long-chain polyunsaturated fatty acids promote paclitaxel cytotoxicity via inhibition of the MDR1 gene in the human colon cancer Caco-2 cell line. J Am Coll Nutr. 2011;30(4):265-273.

18. Aoki T, Narumiya S. Prostaglandins and chronic inflammation. Trends Pharmacol Sci. 2012;33(6):304-311

19. Zibell G, Unkruer B, Pekcec A, Hartz AM, Bauer B, Miller DS, Potschka H. Prevention of seizure-induced up-regulation of endothelial P-glycoprotein by COX-2 inhibition. Neuropharmacology. 2009;56(5):849-855.

20. Beck R, Bertolino S, Abbot SE, Aaronson PI, Smirnov SV. Modulation of arachidonic acid release and membrane fluidity by albumin in vascular smooth muscle and endothelial cells. Circ Res. 1998;83(9):923-931.

21. Sharom FJ. Complex Interplay between the P-Glycoprotein Multidrug Efflux Pump and the Membrane: Its Role in Modulating Protein Function. Front Oncol. 2014;(4):41:1-19. 
22. Das UN, Madhavi N, Sravan Kumar G, Padma M, Sangeetha P. Can tumour cell drug resistance be reversed by essential fatty acids and their metabolites? Prostaglandins Leukot Essent Fatty Acids. 1998;58(1):39-54.

23. Abulrob AN, Mason M, Bryce R, Gumbleton M. The effect of fatty acids and analogues upon intracellular levels of doxorubicin in cells displaying P-glycoprotein mediated multidrug resistance. J Drug Target. 2000;8(4):247-256.

24. Cantrill CA, Skinner RA, Rothwell NJ, Penny JI. An immortalised astrocyte cell line maintains the in vivo phenotype of a primary porcine in vitro blood-brain barrier model. Brain Res. 2012;1479:17 -30.

25. Skinner RA, Gibson RM, Rothwell NJ, Pinteaux E, Penny JI. Transport of interleukin-1 across cerebromicrovascular endothelial cells. Br J Pharmacol. 2009;156(7):1115-1123.

26. Dinarello CA. Interleukin-1 in the pathogenesis and treatment of inflammatory diseases. Blood. 2011;117(14):3720-3732.

27. Tsai SJ. Effects of interleukin-1beta polymorphisms on brain function and behavior in healthy and psychiatric disease conditions. Cytokine Growth Factor Rev. 2017;37:89 97.

28. Denes A, Pinteaux E, Rothwell NJ, Allan SM. Interleukin-1 and stroke: biomarker, harbinger of damage, and therapeutic target. Cerebrovasc Dis. 2011;32(6):517-527.

29. Hartz AM, Bauer B, Fricker G, Miller DS. Rapid regulation of P-glycoprotein at the blood-brain barrier by endothelin-1. Mol Pharmacol. 2004;66(3):387-394.

30. Kim EK, Choi EJ. Compromised MAPK signaling in human diseases: an update. Arch Toxicol. 2015;89(6):867-882.

31. Verma G, Datta M. The critical role of JNK in the ER-mitochondrial crosstalk during apoptotic cell death. J Cell Physiol. 2012;227(5):1791-1795.

32. Iqbal M, Gibb W, Matthews SG. Corticosteroid regulation of P-glycoprotein in the developing blood-brain barrier. Endocrinology. 2011;152(3):1067-1079. 
33. Iqbal M, Baello S, Javam M, Audette MC, Gibb W, Matthews SG. Regulation of Multidrug Resistance P-Glycoprotein in the Developing Blood-Brain Barrier: Interplay between Glucocorticoids and Cytokines. J Neuroendocrinol. 2016;28(3):12360 - 12378.

34. Gelsomino G, Corsetto PA, Campia I, Montorfano G, Kopecka J, Castella B, Gazzano E, Ghigo D, Rizzo AM, Riganti C. Omega 3 fatty acids chemosensitize multidrug resistant colon cancer cells by down-regulating cholesterol synthesis and altering detergent resistant membranes composition. Mol Cancer. 2013;(12):137:1-20.

35. Shaikh SR. Biophysical and biochemical mechanisms by which dietary N-3 polyunsaturated fatty acids from fish oil disrupt membrane lipid rafts. J Nutr Biochem. 2012;23(2):101-105.

36. Shaikh SR, Kinnun JJ, Leng X, Williams JA, Wassall SR. How polyunsaturated fatty acids modify molecular organization in membranes: insight from NMR studies of model systems. Biochim Biophys Acta. 2015;1848(1 Pt B):211-219.

37. Yamamoto K, Ando J. Endothelial cell and model membranes respond to shear stress by rapidly decreasing the order of their lipid phases. J Cell Sci. 2013;126(Pt 5):12271234. 
Table 1.

\begin{tabular}{|c|c|c|c|c|}
\hline & No PUFA & $\begin{array}{c}\mathbf{A A} \\
\mathbf{3 \mu M}\end{array}$ & $\begin{array}{l}\text { DHA } \\
5 \mu \mathrm{M}\end{array}$ & $\begin{array}{l}\text { EPA } \\
\mathbf{3} \mu \mathbf{M}\end{array}$ \\
\hline No DX & $100.0 \pm 13.3$ & $\begin{array}{c}137.1 \pm 11.2 \\
\S \S \S \S\end{array}$ & $\begin{array}{c}119.7 \pm 8.6 \\
\S\end{array}$ & $\begin{array}{c}126.7 \pm 11.4 \\
\S \S \S\end{array}$ \\
\hline $\begin{array}{c}\text { DX } \\
10 \mu M\end{array}$ & $\begin{array}{c}78.7 \pm 7.8 \\
\quad \# \# \#\end{array}$ & $\underset{* * * *}{114.8 \pm 18.4}$ & $\begin{array}{c}89.9 \pm 16.7 \\
\mathrm{~ns}\end{array}$ & $\begin{array}{c}94.6 \pm 11.4 \\
*\end{array}$ \\
\hline No HC & $100.0 \pm 8.9$ & $\begin{array}{c}164.6 \pm 34.8 \\
\S \S \S\end{array}$ & $\begin{array}{c}162.1 \pm 29.5 \\
\S \S \S \S\end{array}$ & $\begin{array}{c}158.2 \pm 22.8 \\
\S \S \S \S\end{array}$ \\
\hline $\begin{array}{c}\mathrm{HC} \\
10 \mu \mathrm{M}\end{array}$ & $\begin{array}{c}79.7 \pm 12.4 \\
\#\end{array}$ & $\begin{array}{c}126.6 \pm 23.0 \\
* * * *\end{array}$ & $\begin{array}{c}100.3 \pm 23.3 \\
\mathrm{~ns}\end{array}$ & $\begin{array}{c}108.4 \pm 22.3 \\
* *\end{array}$ \\
\hline No IL-1及 & $100.0 \pm 9.3$ & $\begin{array}{c}166.3 \pm 43.8 \\
\S \S \S \S\end{array}$ & $\begin{array}{c}173.9 \pm 42.1 \\
\S \S \S \S\end{array}$ & $\begin{array}{c}130.8 \pm 15.1 \\
\S\end{array}$ \\
\hline $\begin{array}{c}\text { IL-1及 } \\
1 \text { ng.ml }\end{array}$ & $\begin{array}{c}74.7 \pm 7.9 \\
\quad \# \# \# \#\end{array}$ & $\underset{* * * *}{107.3 \pm 24.6}$ & $\begin{array}{c}90.95 \pm 11.1 \\
*\end{array}$ & $\underset{* *}{100.0} \pm 21.2$ \\
\hline
\end{tabular}


Figure 1 
A

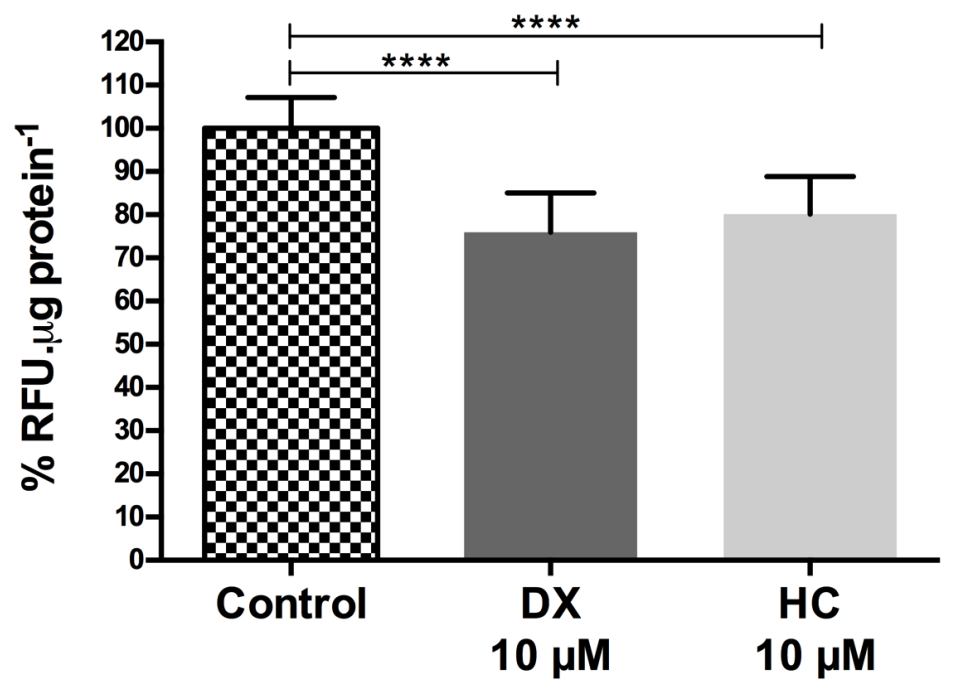

B

$\mathrm{kDa}$

220 -

150 -

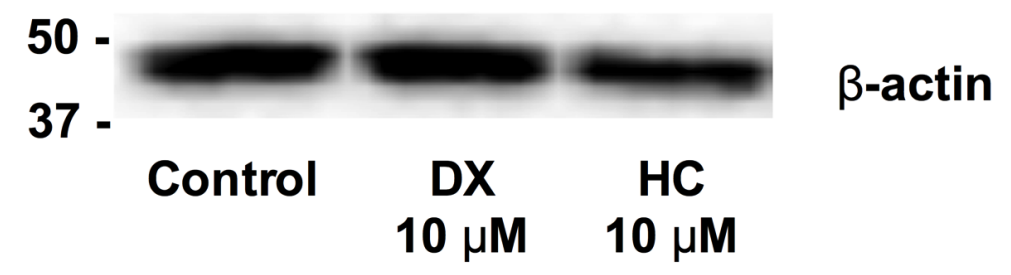

C

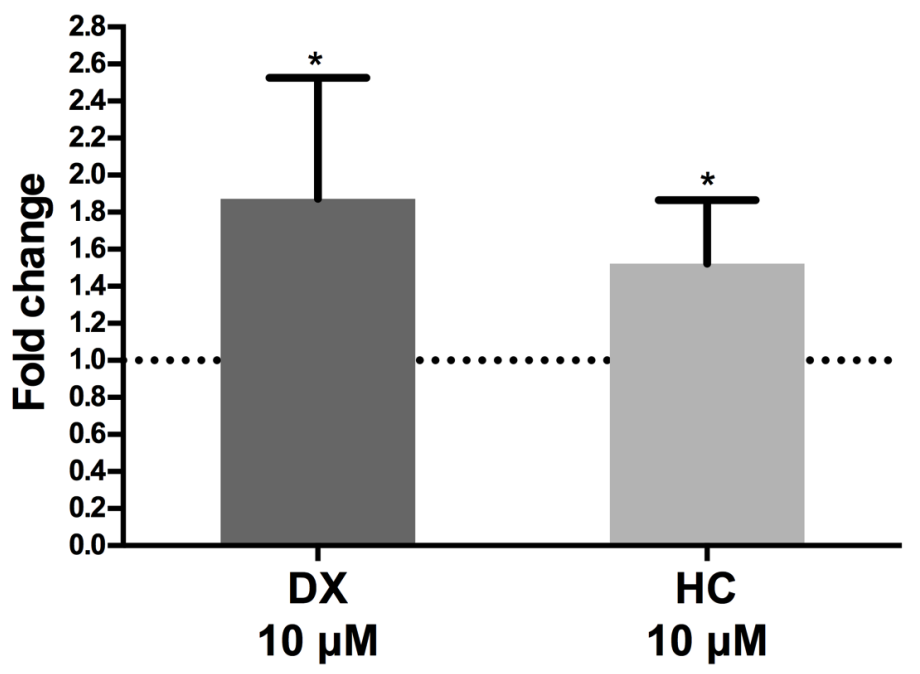


Figure 2

A

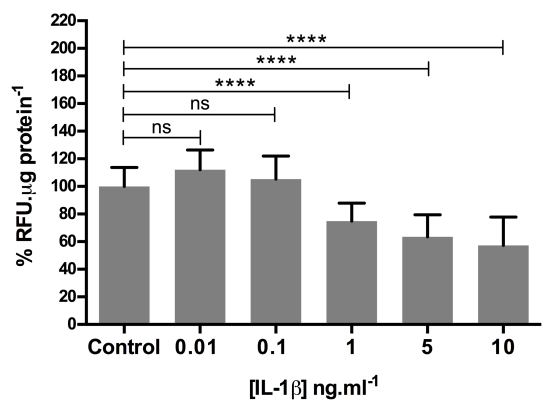

C

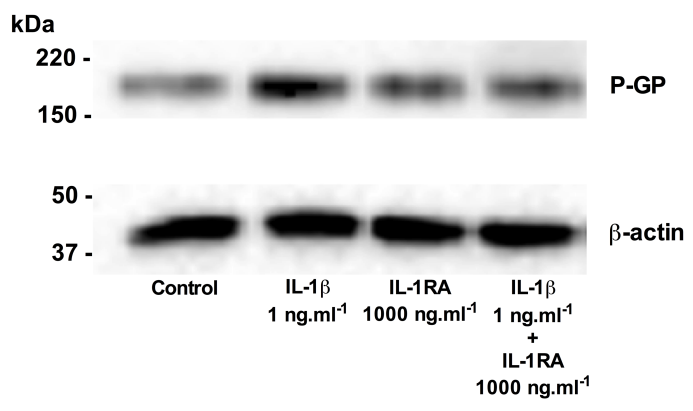

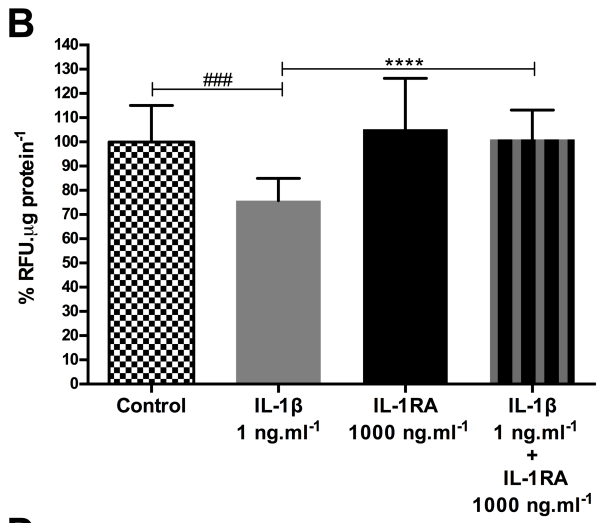

D

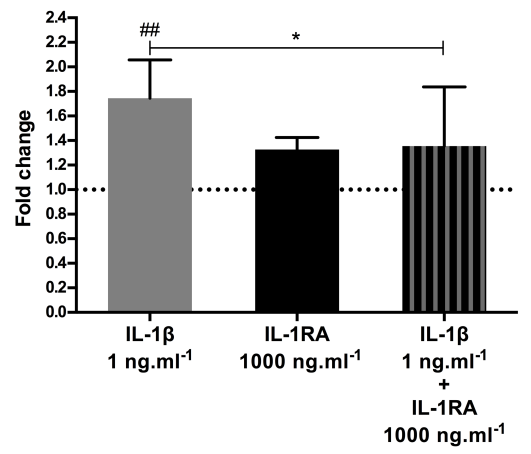


Figure 3

A

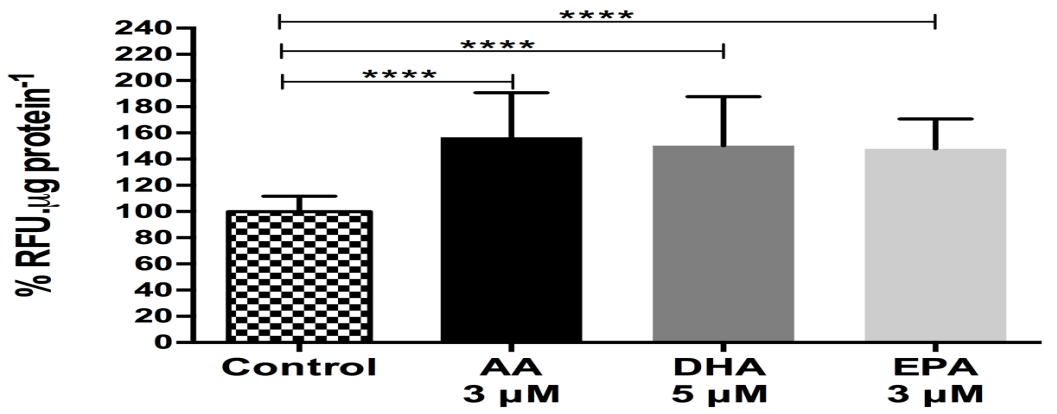

B

\section{kDa}

220 -

150 -

P-GP

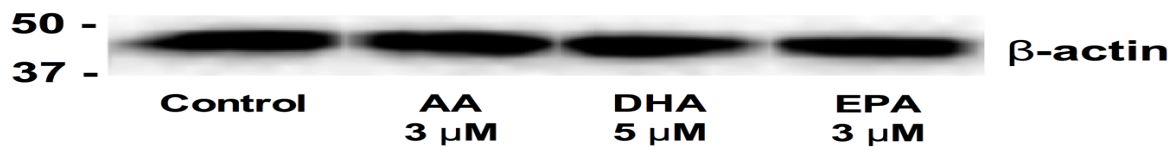

C

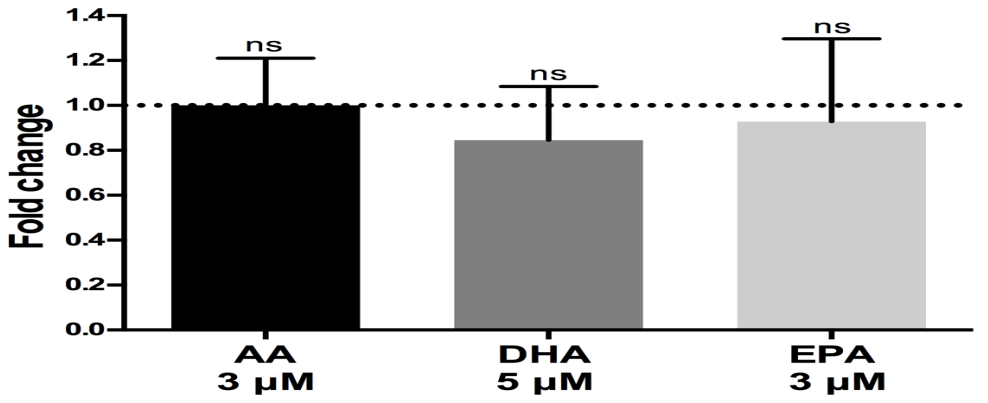


Figure 4
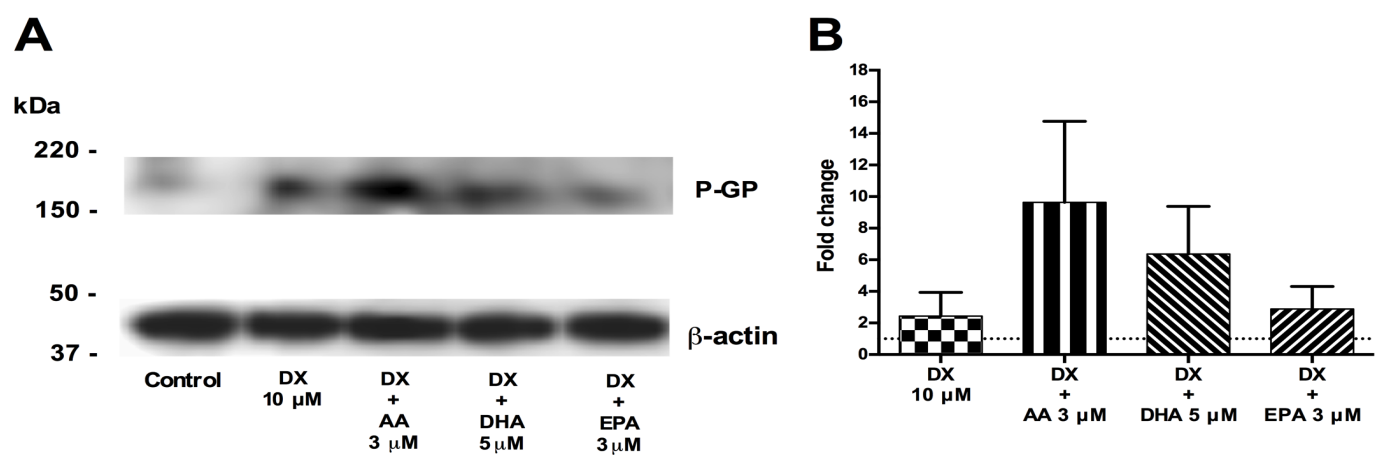

C

D
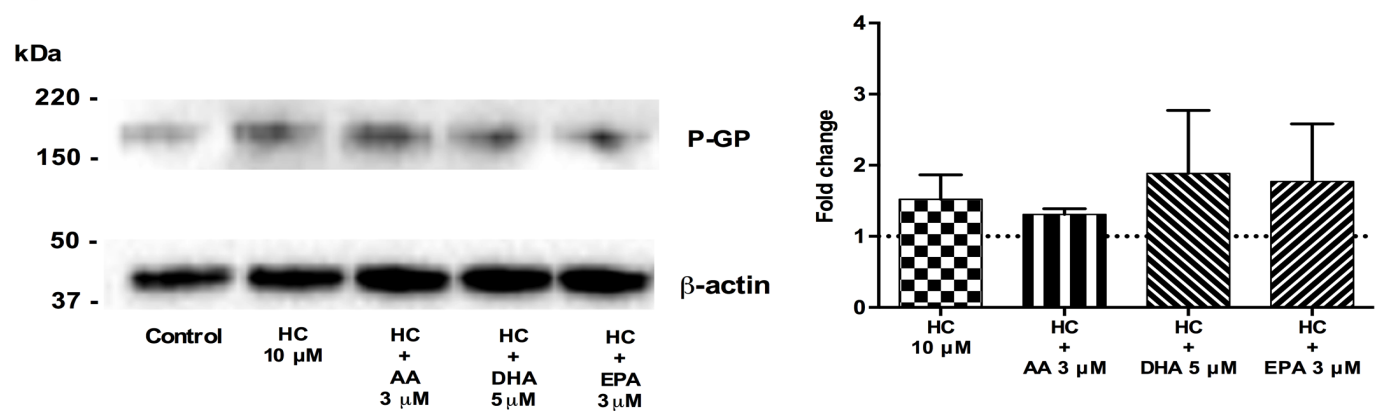

E

F

kDa
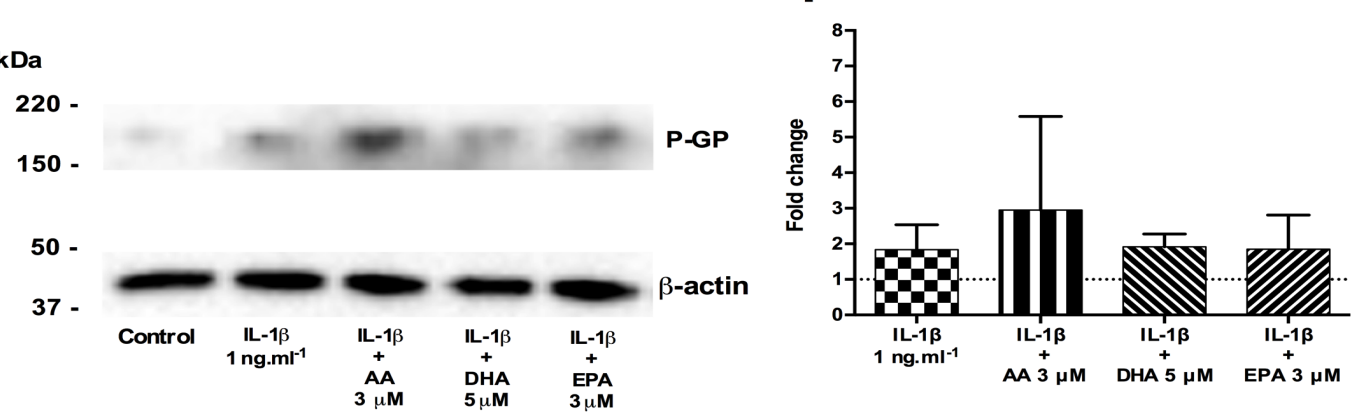
Figure 5

A

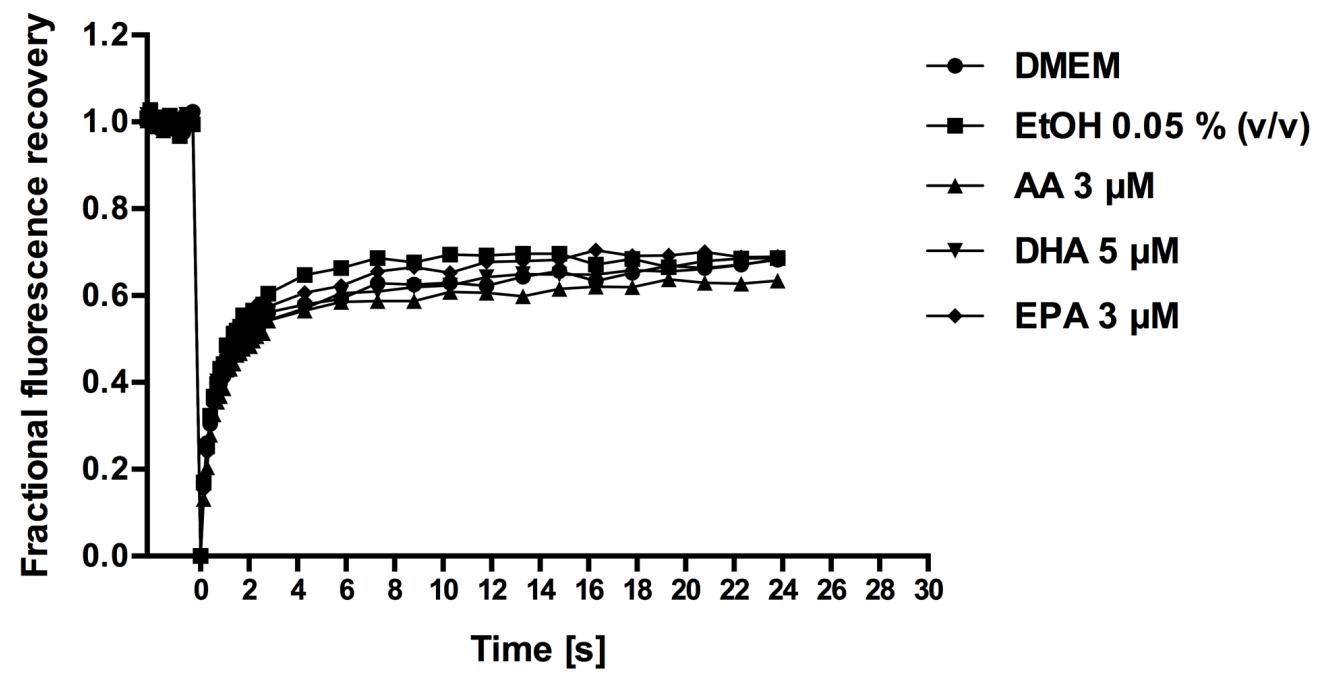

B

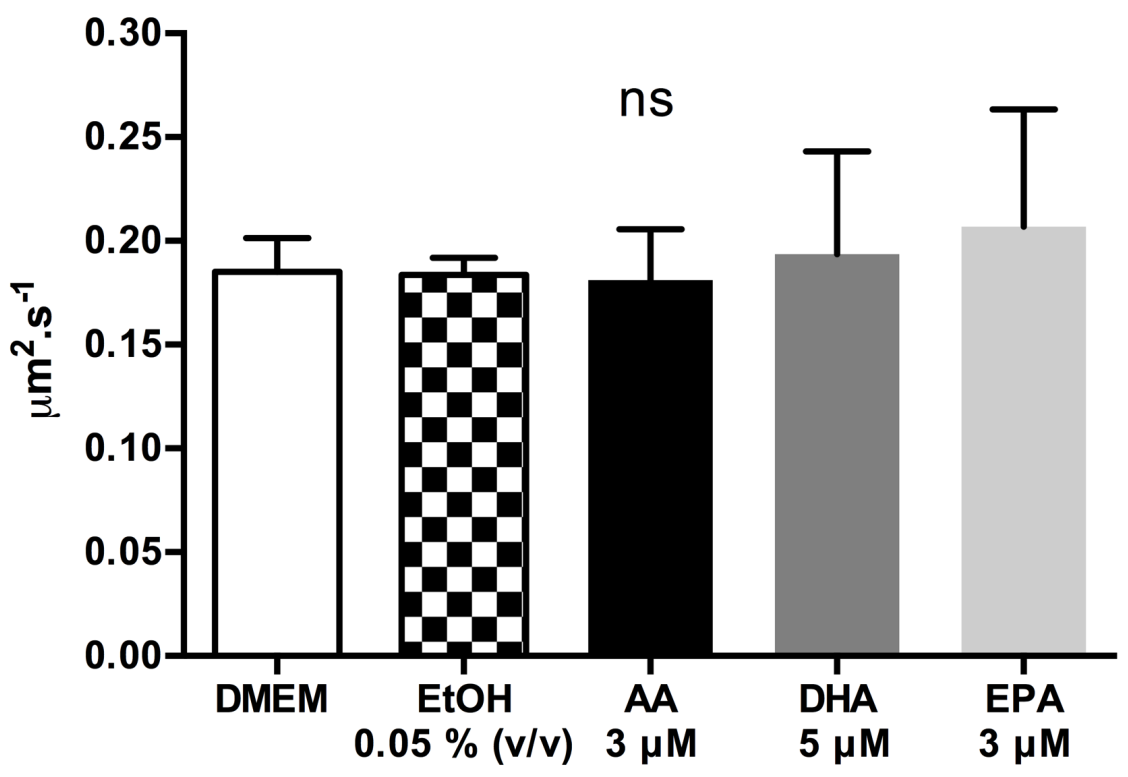

